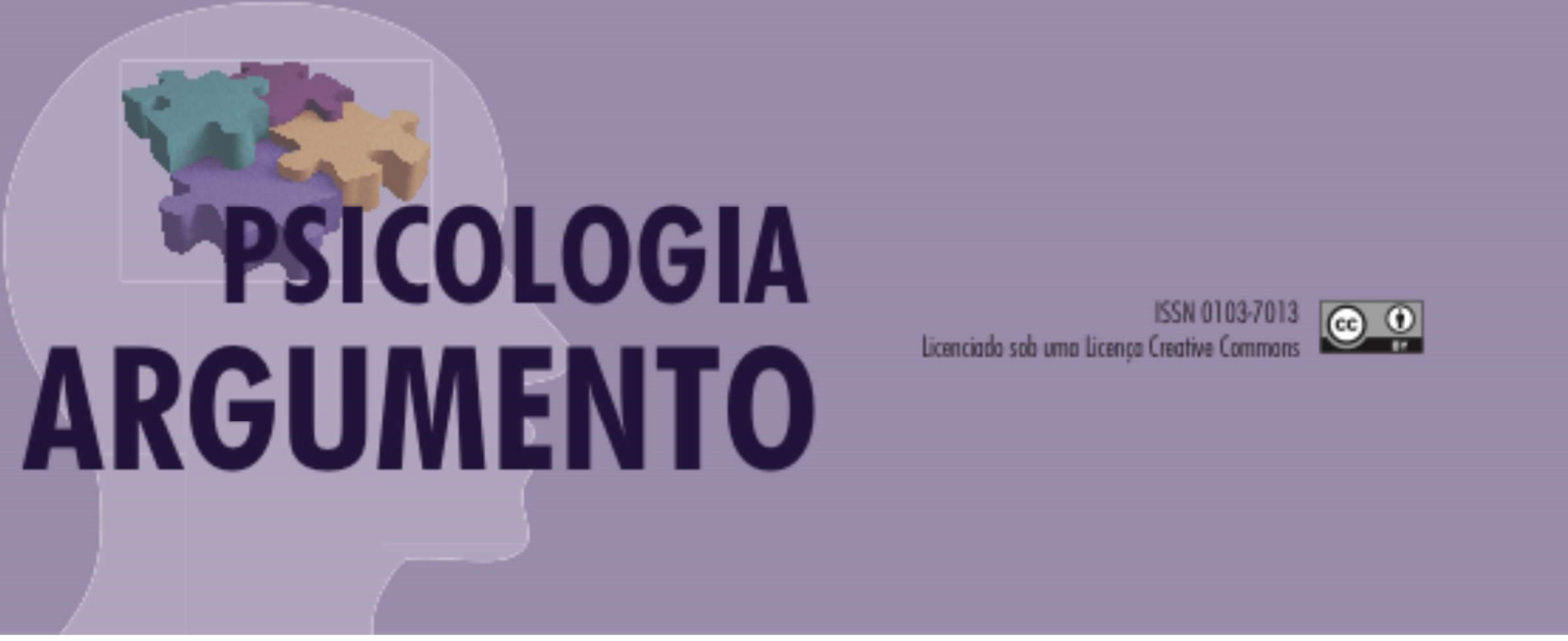

doi: http://dx.doi.org/10.7213/psicolargum. 39.104.A004

\title{
A Teoria das Representações Sociais em interface com a Psicologia Forense: uma revisão sistemática
}

The Theory of Social Representations in interface with Forensic Psychology: a systematic review

La Teoría de las Representaciones Sociales en interfaz con la Psicología Forense: una revisión sistemática

Juliana Xavier Trevisan - Mestranda em Psicologia pela Universidade Tuiuti do Paraná. Curitiba, Paraná, Brasil,

E-mail: julianaxaviertrevisan@gmail.com,

ORCID: https://orcid.org/0000-0003-2819-3820.

Gislei Mocelin Polli - Doutora em Psicologia

Professora do mestrado em Psicologia - Universidade Tuiuti do Paraná, Curitiba,

Paraná, Brasil.

E-mail: gismocelin@gmail.com

ORCID: https://orcid.org/0000-0001-7254-7441

\section{Resumo}

O presente estudo teve como objetivo realizar uma revisão sistemática das publicações que promovem um diálogo entre a Psicologia Forense e a Teoria das Representações Sociais. Para tanto seguiu-se o modelo da recomendação PRISMA utilizando-se como estratégia de busca as palavras-chave: "representações sociais" OR "representação social" OR "teoria das representações sociais" AND "psicologia forense" OR "psicologia jurídica" OR lei OR judiciário OR judicial e seus equivalentes em inglês e espanhol. O período pesquisado foi de 2008 a setembro de 2019, resultando em 127 artigos, dos quais 14 foram incluídos na presente revisão, 
obedecendo aos critérios de inclusão e exclusão previamente estabelecidos. Observou-se uma maior ênfase nos estudos no âmbito da proteção das crianças e adolescentes, da atuação profissional e da execução da pena. Assim, este estudo possibilitou perceber que a Teoria das Representações Sociais tem sido utilizada pela Psicologia Forense, porém de forma incipiente, havendo ainda um campo vasto para ser explorado de forma a contribuir cada vez mais na compreensão de como os pensamentos do senso comum são processados, organizados e compartilhados dentro da seara jurídica que é tão complexa e dinâmica.

Palavras-chave: psicologia forense, teoria das representações sociais, revisão sistemática.

\begin{abstract}
The present study aimed to conduct a systematic review of publications that promote a dialogue between Forensic Psychology and Theory of Social Representations. To do so, the PRISMA recommendation model was followed using the keywords: "social representations" OR "social representation" OR "social representations theory" AND "forensic psychology" OR "legal psychology" OR law Judicial OR Judicial OR and its equivalents in English and Spanish. The researched period was from 2008 to September 2019, resulting in 127 articles, of which 14 were included in the present review, obeying the inclusion and exclusion criteria previously established. There was a greater emphasis on studies in the field of protection of children and adolescents, professional performance and the execution of the sentence. Thus, this study made it possible to perceive that the Theory of Social Representations has been used by Forensic Psychology, however in an incipient way, with still a vast field to be explored in order to contribute more and more in the understanding of how common sense thoughts are processed, organized and shared within the legal area that is so complex and dynamic.
\end{abstract}

Keywords: forensic psychology; theory of social representations; systematic review.

\title{
Resumen
}

El presente estudio tuvo como objetivo realizar una revisión sistemática de publicaciones que promueven un diálogo entre la psicología forense y la teoría de las representaciones sociales. Para hacerlo, se siguió el modelo de recomendación PRISMA usando las palabras clave: "representaciones sociales" $O$ "representación social" $O$ "teoría de representaciones sociales" $Y$ "psicología forense" $O$ "psicología legal” O ley Judicial OR Judicial OR y sus equivalentes en inglés y español. El periodo investigado fue de 2008 a septiembre de 2019, resultando en 127 artículos, de los cuales 14 fueron incluidos en la presente revisión, obedeciendo los criterios de inclusión y exclusión previamente establecidos. Se hizo mayor hincapié en los estudios en el campo de la protección de niños y adolescentes, el desempeño profesional y la ejecución de la sentencia. Por lo tanto, este estudio permitió darse cuenta de que la Teoría de las Representaciones Sociales ha sido utilizada por la Psicología Forense, sin embargo de una manera incipiente, con todavía un vasto campo por explorar para contribuir cada vez más en la comprensión de cómo se procesan los pensamientos de sentido común, organizado y compartido dentro del área legal que es tan compleja y dinámica.

Palabras clave: psicología forense, teoría de las representaciones sociales, revisión sistematica.

\section{Introdução}


A Psicologia Forense tem como objeto de estudo a interface entre o Direito e a Psicologia. Gomide (2016) a conceitua como sendo "a área de conhecimento que tem algum tipo de envolvimento com o Direito, seja cível ou criminal". Todavia, há doutrinadores que preferem o termo Psicologia Jurídica por ser mais abrangente, compreendendo a ciência do Direito como um todo, ao passo que o termo forense estaria mais restrito ao foro judicial (França, 2004).

Neste trabalho será utilizada a nomenclatura Psicologia Forense (Forensic Psychology), termo este empregado pelas principais revistas científicas da área, em língua inglesa (Gomide, 2016). Ressalta-se que na presente pesquisa foram utilizados tanto os artigos que adotaram o termo Psicologia Forense quanto o termo Psicologia Jurídica.

Em seu sentido amplo e dinâmico, a Psicologia Forense pode ser definida como uma área da psicologia responsável por descrever, explicar, prever e intervir no comportamento humano inserido em um contexto jurídico, visando a contribuir para a construção e prática de sistemas jurídicos objetivos e justos (Quintero \& López, 2010). Para esses autores (Quintero \& López, 2010), o comportamento humano é concebido como um conjunto que inclui não só comportamento facilmente observável, mas também os processos cognitivos e emocionais, bem como as crenças e atitudes das pessoas. Para França (2004), essa área de estudo da psicologia deve ir além da análise do comportamento humano, devendo abranger as consequências das ações judiciais sobre o indivíduo, devendo transcender as solicitações do mundo jurídico, uma vez que as decisões judiciais interferem direta e indiretamente nas relações entre as pessoas.

A origem da Psicologia Forense se deu no século XIX, na área da psiquiatria forense, diante da necessidade da realização da perícia para a realização da análise da saúde mental do indivíduo réu em processo criminal. Seu maior crescimento ocorreu a partir de 1970, expandindo sua área de atuação. A especialização em Psicologia Forense no Brasil foi criada pelo Conselho Federal de Psicologia em 2001 por meio da Resolução 02/2001(Gomide, 2016). As áreas do Direito em que há uma atuação mais forte da Psicologia são Direito Penal, Direito da Criança e Adolescente, Direito do Trabalho e Direito Civil, no qual se sobressai o ramo do Direito de Família, âmbitos em que o psicólogo pode necessitar atuar no processo como avaliador, perito, mediador, terapeuta ou orientador (Lago, Amato, Teixeira, Rovinski \& Bandeira, 2009). 
Gomide (2016) cita oito principais áreas de atuação do psicólogo forense: psicologia do crime, avaliação forense, clínica forense, psicologia do sistema correcional, psicologia aplicada aos programas de prevenção, psicologia da polícia, assessoria e pesquisa. Dessa forma, atualmente a Psicologia Forense não fica restrita apenas à atividade de cunho avaliativo e de subsídio aos magistrados para sua tomada de decisão, embora assim atue de forma predominante (Lago, et al., 2009).

O meio científico busca incessantemente uma visão mais ampla do seu objeto de estudo e para isso muitas vezes faz-se necessária uma integração entre as diversas áreas do conhecimento. Referida integração traz olhares diferentes sobre o mesmo objeto de estudo, visando à construção conjunta do conhecimento, mudando a forma de percepção da realidade, pois passa a abranger múltiplos aspectos simultaneamente. Essa maior atuação da Psicologia no campo do Direito visa a torná-lo mais humanizado, trazendo um novo olhar para os sujeitos do Direito como réus, vítimas, testemunhas, agentes de segurança e operadores do Direitos (juízes, promotores, advogados, delegados, servidores públicos), de forma a analisar e refletir sobre crenças e comportamentos (Gomide, 2016).

Levine (2019) pontua que o sistema jurídico como um todo utiliza-se das informações fornecidas pela psicologia jurídica no seu dia-a-dia, devendo os advogados e juízes estarem também preparados para trabalhar com as informações trazidas pelos profissionais de psicologia. O Conselho Nacional de Justiça (CNJ, 2019) baixou a resolução n.75, por meio da qual tornou obrigatório para todos os Tribunais do país a exigência de questão discursiva sobre a matéria de psicologia judiciária quando da elaboração das provas de concurso para ingresso nos quadros da magistratura, de forma a exigir dos novos juízes um conhecimento além do Direito puro e simples, exigido até então.

Não se pode deixar de mencionar a importância da Psicologia Forense no auxílio da evolução do Direito por meio também da orientação dos legisladores que ditam as normas sobre o comportamento humano, suas faculdades e inclinações, que na sequência serão aplicadas na sociedade pelos operadores do Direito (Diniz, 2000). Via de regra, a alteração legislativa gera mudanças de comportamentos na sociedade, positivas ou negativas, e por via de consequência alteram o rumo de sua história, pois "a atividade do ser humano sempre se exterioriza através de suas relações com seus semelhantes, ou de 
sua ação sobre bens, materiais ou imateriais, que lhe proporcionam os meios de conservação e desenvolvimento" (Ráo, 1999, p. 51).

As crenças e comportamentos pessoais estão intrinsecamente ligadas às comunicações interindividuais, e como o Direito tem por objetivo regular as relações entre as pessoas na sociedade, de forma a trazer a pacificação dos conflitos (Ráo, 1999), referidas crenças e comportamentos geram consequências no mundo jurídico, razão pela qual justifica o estudo dos temas de Psicologia Forense sob a ótica da Teoria das Representações Sociais (TRS), visando compreender a relação do sujeito com o meio em que vive e atua.

A TRS nasceu com Serge Moscovici, em Paris, em seu estudo Psychanalyse: Son image et son public, em 1961. Esta obra decorre de um trabalho empírico, resultado de entrevistas e questionários com uma amostra de 2.265 sujeitos, análise de conteúdo sobre 1.640 artigos da imprensa, publicados em 230 jornais e revistas entre janeiro de $1952 \mathrm{e}$ julho de 1956, por meio do qual estudou as opiniões, as atitudes e os estereótipos a respeito de conceitos da psicanálise pela população francesa (Moscovici, 2012).

Influenciado por Durkheim, Weber, Simmel e Lévy-Bruhl, Moscovici observou que determinados conceitos da psicanálise estavam sendo utilizados no dia-a-dia das pessoas, não ficando mais restrito apenas ao meio acadêmico (Lahlou, 2014). Diante disso, ele detectou que o conhecimento pode estar presente em dois universos, mais precisamente no científico, também denominado de reificado, e no consensual, cotidiano, os quais possuem conceitos e formas de constituição diferentes, embora este sofra influência daquele. A TRS tem por objeto de estudo o conhecimento consensual, ou seja, o conhecimento compartilhado entre as pessoas em determinados grupos de classes (Polli \& Camargo, 2015).

Embora Moscovici não tenha apresentado uma definição fechada sobre as representações sociais, referiu-se a elas como "um conjunto de conceitos, afirmações e explicações originadas no quotidiano, no decurso de comunicações interindividuais" (Moscovici, 1982. p.1). De acordo com Jodelet (2001, p.22), as representações sociais são "uma forma de conhecimento, socialmente elaborada e partilhada, com um objetivo prático, e que contribui para a construção de uma realidade comum a um conjunto social”. Segundo esta autora, trata-se de um saber do senso comum e não científico. 
Atualmente, como afirma Jodelet (2001), a Teoria das Representações Sociais tem possibilitado a teóricos e acadêmicos traçar um novo olhar para o motivo e o modo pelo qual as pessoas fazem o que fazem, construindo o grupo social uma identidade em cada momento histórico, inclusive no que se refere às suas regras. A importância de seu estudo está na necessidade de "compreender e identificar como ela atua na motivação das pessoas ao fazer determinado tipo de escolha" (Oliveira \& Werba, 2013, p.107).

Para Spink (1993) a TRS visa estudar as formas de conhecimento, razão pela qual se torna complementar às demais ciências que têm por objeto o conhecimento como a Filosofia, a História, a Sociologia e a Psicologia Cognitiva, tendo um caráter de transversalidade. Todavia, este conhecimento objeto das Representações Sociais (RS) é o conhecimento do senso comum, prático, e não aquele formalizado, com rigor lógico e metodológico.

As RS trazem para o campo do Direito um novo olhar, um olhar atento, não apenas ao mundo das normas, do ser e do dever ser, mas dos entrelaçamentos dos sujeitos pensantes inseridos em determinado grupo social, procurando fazer compreender como o indivíduo constrói a sua realidade (Lahlou, 2014). Moscovici (1982), defende a ideia de que vivemos numa sociedade pensante, composta por seres humanos que pensam e interagem em seus pensamentos de forma autônoma, construindo e desconstruindo representações em seu cotidiano. Logo, no mundo jurídico não há apenas o conhecimento reificado, mas sim uma simbiose entre este e o conhecimento consensual. Ainda, Polli e Camargo (2010, p.13) entendem que a teoria "busca explicar e entender como ocorre o processo de criação do pensamento social, como ele se mantém ou se modifica, entre outros fatores".

Um dos grandes motivos pelos quais as pessoas constroem as representações sociais, segundo Moscovici (1982), é para tornar familiar o não familiar, em conhecido o desconhecido, e isso poderá se dar por meio do processo de ancoragem e objetivação, elementos formadores das RS. Trata-se da forma como se adquire o conhecimento, tendo como base de atuação o campo da memória.

A ancoragem é o processo que visa a classificar o não conhecido por meio de buscas na memória de um protótipo de forma a torná-lo conhecido, em outras palavras, é o processo de assimilação do novo ao que já existe e é conhecido. Segundo Oliveira e 
Werba (2013, p.109), “quando determinado objeto, ou ideia, é comparado ao paradigma de uma categoria, ele adquire características dessa categoria e é reajustado para que se enquadre nela", ou seja, mudam-se seus valores e sentimentos para que ocorra essa adaptação.

Nesse caso, segundo Moscovici (1982), a memória é dirigida para dentro e o mais importante são as convenções e memórias dessa categoria e não os seus julgamentos, pois estes decorrem daqueles e, embora sejamos conscientes dessa disparidade, somos incapazes de eliminá-la. Uma representação é ancorada por meio da classificação e nomeação, que produzem três efeitos:

(a) uma vez que um nome tenha sido imputado, o objeto e pessoa pode ser descrito e certas qualidades, intenções, etc, podem ser imputadas a ele; (b) pode ser distinguido de outros objetos ou pessoas pelas suas qualidades ou imputações;

(c) se torna sujeito a uma convenção entre aqueles que o utilizam e dividem a mesma convenção" (Moscovici, 1982, p.10)

No que se refere à objetivação, trata-se de um processo por meio do qual se torna visível uma realidade até então desconhecida pela sua abstração, por meio da associação dessa a determinada imagem conhecida, tornando, assim, o abstrato em concreto. Como esclarece Moscovici (1982, p.13), diversamente da ancoragem, ela tende a se dirigir para fora, derivando "de conceitos e imagens da memória a fim de combiná-los e reproduzilos no mundo externo, para criar algo novo para que se o veja com o auxílio do que já foi visto."

Em relação às diferentes abordagens da TRS adotou-se no presente estudo a classificação proposta por Moliner e Guimelli (2015). Segundo esses autores, a Teoria das Representações Sociais possui quatro abordagens, a sociogenética, a estrutural, a sociodinâmica e a dialógica. A abordagem sociogenética tem como principais autores Moscovici e Jodelet, os quais visam compreender as forças geradoras das representações sociais utilizando para tanto o estudo aprofundado da ancoragem e objetivação, com focona informação, no campo da representação e na atitude, que são as três dimensões das RS.

A abordagem estrutural, defendida por Abric e Flament,postula que as representações sociais possuem dois sistemas com características e funções distintas, 
porém complementares entre si, o sistema central e o sistema periférico. O sistema central é composto pelo núcleo central das representações sociais, tendo como principais características ser normativo, estável, coerente, resistente às mudanças, relativamente independente do contexto social e material e homogêneo, ao passo que o sistema periférico é funcional, mais flexível, adaptativo e relativamente homogêneo (Abric, 1993; Polli \& Wachelke, 2013).

A abordagem sociodinâmica, defendida por W. Doise, busca compreender articulações entre o funcionamento cognitivo e o sistema de crenças compartilhadas. Trata-se de uma perspectiva mais sociológica que dá ênfase ao pertencimento social das pessoas na formação das RS. Busca conectar o individual ao coletivo, trazendo explicações que articulam as duas esferas, utilizando-se para isso da interação de quatro níveis: o intrapessoal, o interpessoal, o grupal e o societal (Sá, 2002; Almeida, 2009).

Por fim, há a abordagem dialógica proposta por Marková (2006), a qual estuda as representações sociais sob o ponto de vista da dialogicidade, enfatizando o papel da comunicação e da linguagem na formação e compartilhamento das RS. Para esta autora esses processos devem estar no centro dos estudos em Psicologia Social.

Observa-se que a TRS pode ser de grande auxílio para entendimento de como os pensamentos coletivos do senso comum ligados à área do Direito são processados, organizados e compartilhados, e como têm influenciado nas relações jurídicas, uma vez que o Direito é uma ciência essencialmente humana e dinâmica que pretende regular as práticas sociais. Portanto, torna-se importante identificar os estudos científicos que visem a compreender temas centrais na área da Psicologia Forense sob a perspectiva da Teoria das Representações Sociais.

Não foram identificados estudos científicos de revisão sistemática a respeito da aplicação da Teoria das Representações Sociais no âmbito da Psicologia Forense nas principais bases de dados de artigos acadêmicos (Sage Journals, BVS-psi, PePSIC, APA PsycNET e Google Scholar), o que demonstra a necessidade do presente estudo de revisão. Assim, na presente pesquisa busca-se fazer uma análise sobre o estudo da Teoria das Representações Sociais no âmbito da Psicologia Forense, isto é, o quanto o conhecimento do senso comum tem sido investigado no campo jurídico. Logo, para a 
realização desta pesquisa de revisão foi questionado quais diálogos têm sido estabelecidos entre a Teoria das Representações Sociais e a Psicologia Forense.

\section{Método}

Neste estudo seguiu-se o modelo da recomendação PRISMA (Preferred Reporting Items for Systematic Reviews and Meta-analyses) (Moher, Liberati, Tetzlaff, Altman \& The PRISMA Group, 2009) para a elaboração da revisão sistemática de literatura científica. O levantamento dos estudos científicos foi realizado por meio de pesquisa entre os dias 09 e 25 de setembro de 2019 nas seguintes bases de dados: Sage Journals, BVSpsi, PePSIC e APA PsycNET, publicados no período de 2008 a outubro de 2019, escritos na língua portuguesa, inglesa ou espanhola, utilizando-se as seguintes palavras-chaves associadas diretamente à questão da pesquisa: ("representações sociais" OR "representação social" OR "teoria das representações sociais" OR "representaciones sociales" OR "representación social” OR "teoria de las representaciones sociales" OR "social representations" OR "social representation"OR"social representations theory") AND ("psicologia forense” OR "psicologia jurídica” OR "psicología jurídica” OR "psicología forense” OR "forensic psychology" OR "legal psychology” OR "lei” OR "ley” OR "law" OR justiça OR “justicia” OR “justice” OR “judiciário” OR “judicial”). A estratégia de busca foi adaptada às características de cada base de dados.

Inicialmente optou-se por buscar estudos mais recentes, sendo realizada a pesquisa de artigos científicos publicados nos últimos cinco anos. Todavia, foram identificados apenas 74 artigos científicos, razão pela qual foi decido ampliar a pesquisa para o período entre 2008 e 2019 visando assim atingir uma visão mais completa dos artigos escritos na área dentro de um período que ainda pode ser considerado recente. Para armazenar estudos coletados e facilitar a exclusão de duplicidade foi elaborada uma planilha no programa Excel contendo as seguintes informações: base de dados, título do periódico, nome do autor, ano de publicação, revista, se empírico ou não, objetivos e resultados. 
Elegeu-se como critério de inclusão: a) artigos científicos empíricos aplicando a Teoria das Representações Sociais, escritos na língua portuguesa, inglesa ou espanhola; b) estudos de Psicologia Forense. Ainda na primeira fase da triagem decorrente da análise do título e resumo, foram adotados critérios de exclusão em virtude do conteúdo apresentado: a) não utilização da TRS, mas apenas do termo 'representações sociais' como sinônimo de crenças sociais em sentido amplo; b) estudos de cenários políticos e não jurídicos; c) não aplicação da TRS de forma empírica; d) análise de questões sob prisma filosófico ou político e não jurisdicional; e) estudos de revisão de literatura.

\section{Resultados}

A estratégia de busca resultou em um total de 127 estudos, conforme representado na Figura 1, sendo excluídos 13 por duplicidade, restando 114. Na sequência foram excluídos 93 pela leitura do título e resumo, conforme critérios de exclusão, resultando em 21 artigos.

Por fim, após a leitura integral de cada texto, foram excluídos sete artigos, dentre eles de Rumin, Nascimento Ferrari, Faria Barros, Cardozo e Cavalhero (2011); Manso e Almeida (2009); Bussinger e Novo (2008); de Lima e Mota (2015) e Kolind, Frank, Lindberg, e Tourunen, (2015) por não utilizarem a TRS, mas apenas o termo 'representações sociais' como sinônimo de crenças sociais em sentido amplo; Machado e Porto (2015) porque o método não restou claro e não se pode compreender o processo de análise dos dados; e, ao final, o artigo de Eloy, Consuelo e Biacchi (2010), por não se tratar de um estudo empírico sobre a Teoria das Representações Sociais, mas de uma reflexão da própria autora com base na sua experiência profissional enquanto psicóloga forense; resultando em 14 artigos científicos incluídos na presente revisão sistemática conforme consta na Figura 1 e Tabela 1.

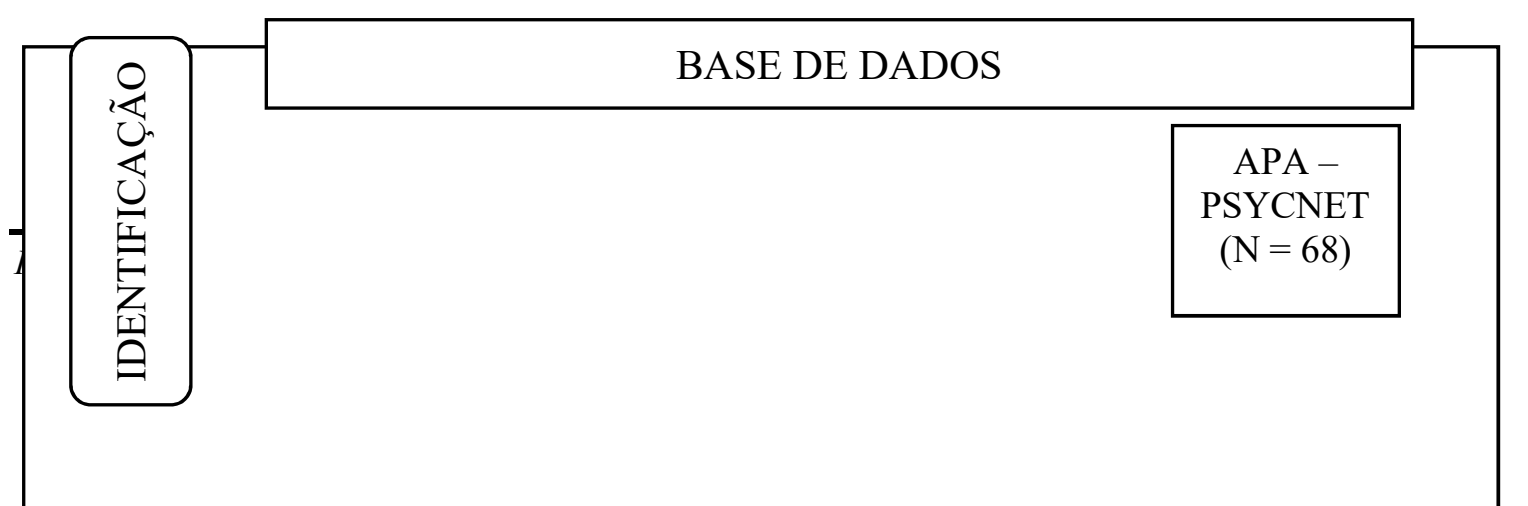




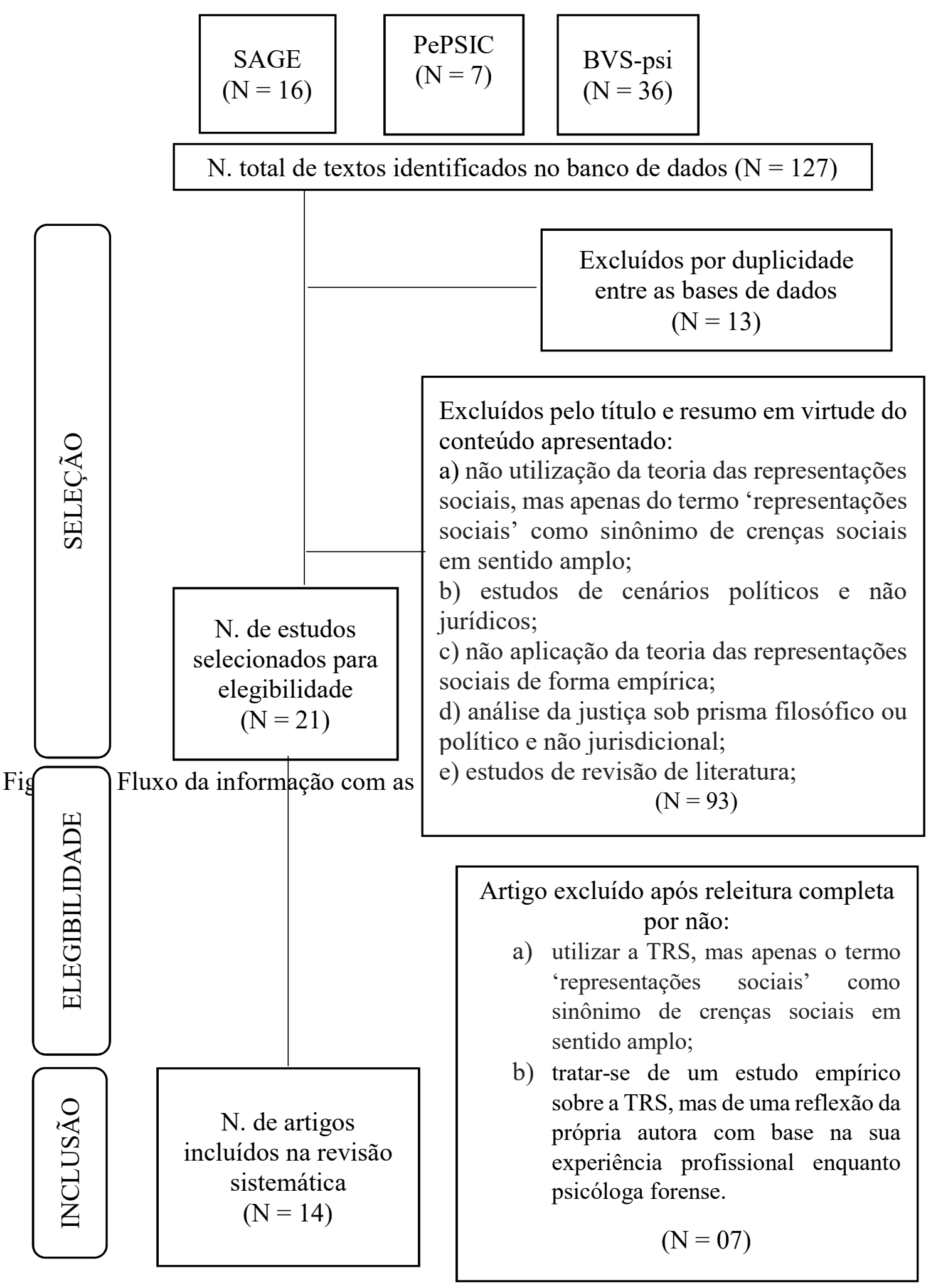


Figura 1 - Fluxo da informação com as diferentes fases da revisão sistemática

Tabela 1 - Sumário das características básicas dos artigos científicos incluídos na revisão sistemática.

\begin{tabular}{|c|c|c|c|c|c|}
\hline $\begin{array}{c}\text { Autores/ } \\
\text { Título }\end{array}$ & Participantes & Instrumento & & $\begin{array}{c}\text { Processamento } \\
\text { dos dados }\end{array}$ & $\begin{array}{c}\text { Abordagem da } \\
\text { TRS }\end{array}$ \\
\hline $\begin{array}{l}01 \text { - Ikuma, D. M., Kodato, } \\
\text { S. \& Sanches, N. A. } \\
\text { Significados de atos } \\
\text { infracionais praticados por } \\
\text { adolescentes em conflito com } \\
\text { a lei }\end{array}$ & 07 adolescentes & $\begin{array}{l}\text { Entrevistas } \\
\text { semiestruturadas }\end{array}$ & & $\begin{array}{l}\text { Análise de conteúdo } \\
\text { temática }\end{array}$ & Sociogenética \\
\hline $\begin{array}{l}02 \text { - Mafra, V. C. A. S., \& } \\
\text { Santos, M. F.S. } \\
\text { Do novo ao tradicional: a } \\
\text { representação da psicologia } \\
\text { no judiciário }\end{array}$ & $\begin{array}{l}56 \text { psicólogos } \\
\text { forenses }\end{array}$ & $\begin{array}{l}\text { Questionário } \\
\text { evocação livre }\end{array}$ & de & $\begin{array}{l}\text { Análise de evocação } \\
\text { livre }\end{array}$ & Estrutural \\
\hline $\begin{array}{l}03 \text { - Branco, M. A. O., \& } \\
\text { Tomanik, E. A. } \\
\text { Violência doméstica contra } \\
\text { crianças e adolescentes: } \\
\text { prevenção e enfrentamento }\end{array}$ & $\begin{array}{ll}07 & \text { agentes } \\
\text { públicos } & \end{array}$ & $\begin{array}{l}\text { Entrevistas } \\
\text { semiestruturadas }\end{array}$ & & Método dialético & Sociogenética \\
\hline $\begin{array}{l}\text { 04- Coelho, B. I. \& Rosa, E. } \\
\text { M. } \\
\text { Ato infracional e medida } \\
\text { socioeducativa: } \\
\text { Representações de } \\
\text { adolescentes em L. A }\end{array}$ & 46 adolescentes & $\begin{array}{l}\text { Entrevistas } \\
\text { semiestruturadas }\end{array}$ & & $\begin{array}{l}\text { Análise de evocação } \\
\text { livre }\end{array}$ & Estrutural \\
\hline $\begin{array}{l}\text { 05- Coutinho, M. P. L., } \\
\text { Estevam, I. D., Araújo, L. } \\
\text { F. \& Araújo, L. S. } \\
\text { Prática de privação de } \\
\text { liberdade em adolescentes: } \\
\text { Um enfoque } \\
\text { psicossociológico }\end{array}$ & 50 adolescentes & $\begin{array}{l}\text { Entrevistas } \\
\text { semiestruturadas }\end{array}$ & & $\begin{array}{l}\text { Análise de conteúdo } \\
\text { temática }\end{array}$ & Sociogenética \\
\hline $\begin{array}{l}06 \text { - Silva, L. M. P., } \\
\text { Ferriani, M. G. C., \& Silva, } \\
\text { M. A. L. } \\
\text { Judiciary as the last resort to } \\
\text { protect children and } \\
\text { adolescents: Intersectoral } \\
\text { actions, investment in human } \\
\text { resources, and structuring of } \\
\text { services. }\end{array}$ & $\begin{array}{l}17 \text { servidores } \\
\text { públicos }\end{array}$ & $\begin{array}{l}\text { Entrevistas } \\
\text { semiestruturadas } \\
\text { grupo focal }\end{array}$ & $\mathrm{e}$ & $\begin{array}{l}\text { Interpretação dos } \\
\text { sentidos }\end{array}$ & Sociogenética \\
\hline $\begin{array}{l}07 \text { - Almeida, L. F., \& } \\
\text { Santos, M. F. S. } \\
\text { Representações sociais de } \\
\text { violência urbana entre } \\
\text { policiais civis }\end{array}$ & $\begin{array}{ll}108 & \text { agentes } \\
\text { públicos }\end{array}$ & $\begin{array}{l}\text { Questionário } \\
\text { evocação livre } \\
\text { Entrevista }\end{array}$ & & $\begin{array}{l}\text { Análise Prototípica e } \\
\text { CHD }\end{array}$ & $\begin{array}{l}\text { Estrutural } \\
\text { e Sociogenética }\end{array}$ \\
\hline $\begin{array}{l}08 \text { - Estevam, I. D., Lima } \\
\text { Coutinho, M. d. P., \& de } \\
\text { Araújo, L. F. }\end{array}$ & 115 adolescentes & $\begin{array}{l}\text { Questionário } \\
\text { evocação livre }\end{array}$ & de & $\begin{array}{l}\text { Análise de evocação } \\
\text { livre }\end{array}$ & Estrutural \\
\hline
\end{tabular}


Os desafios da prática socioeducativa de privação de liberdade em adolescentes em conflito com a lei: Ressocialização ou exclusão social?

09 - Schneebeli, F. C. F., \& 30 genitores Menandro, M. C. S.

Com quem as crianças ficarão? Representações sociais da guarda dos filhos após a separação conjugal

10 - Laschefski, K. A., Dutra, C., \& Doula, S. M.

17 agricultores A legislação ambiental como com a agricultura foco de conflitos: uma análise familiar

a partir das representações

sociais da natureza dos pequenos agricultores em Minas Gerais, Brasil.

11 - Machado, B. A. \&

Sloniak, M. A.

14 servidores públicos

Disciplina ou ressocialização?

Racionalidades punitivas,

trabalho prisional e política

penitenciária.

12 - Oliveira, E. P. T.

10 mulheres

Mulheres em conflito com a encarceradas

lei: a ressignificação de

identidades de gênero em um

contexto prisional.

13- Rochira, A.

29

Common sense of experts: públicos

Social representations of

justice among professionals.

14 - Sauerbronn, F. F., \&

Sauerbronn, J. F. R.

263 servidores públicos

agentes

Representações sociais da

reforma do Judiciário - um

estudo baseado nas

perspectivas dos servidores do

Tribunal de Justiça do Estado

da Bahia.
Entrevistas com Análise de conteúdo Sociogenética roteiro estruturado e temática

questionário

\section{Entrevista Interpretação livre Sociogenética}

Análise documental e entrevistas em profundidade

Entrevistas semiestruturadas

Entrevistas semiestruturadas

Questionário evocação livre
Análise de discurso Sociogenética

Análise de conteúdo Estrutural

Análise de conteúdo Sociogenética na abordagem

Grounded Theory

de Análise de conteúdo Sociogenética temática

Após análise aprofundada da temática dos 14 artigos restantes, incluídos na presente revisão sistemática, eles foram classificados em três categorias: representações sociais no âmbito (1) do Direito Criminal, composta por três artigos: Oliveira (2009), Machado e Sloniak, (2015) e Laschefski, Dutra e Doula (2012); (2) da proteção à criança e ao adolescente, composta por sete artigos, Schneebeli e Menandro (2014), Branco e 
Tomanki (2018), Silva, Ferriani e Silva (2012), Ikuma, Kodato e Sanches (2013); Coelho e Rosa (2013); Coutinho, Estevam, de Araújo e Araújo (2011); Estevam, de Lima Coutinho e Araújo (2009); e, por fim, a categoria (3) do profissional atuante no cenário jurídico composta por quatro artigos: Mafra e Santos (2013), Sauerbronn e Sauerbronn (2015), Almeida e Santos (2013) e Rochira (2014), conforme Figura 2.

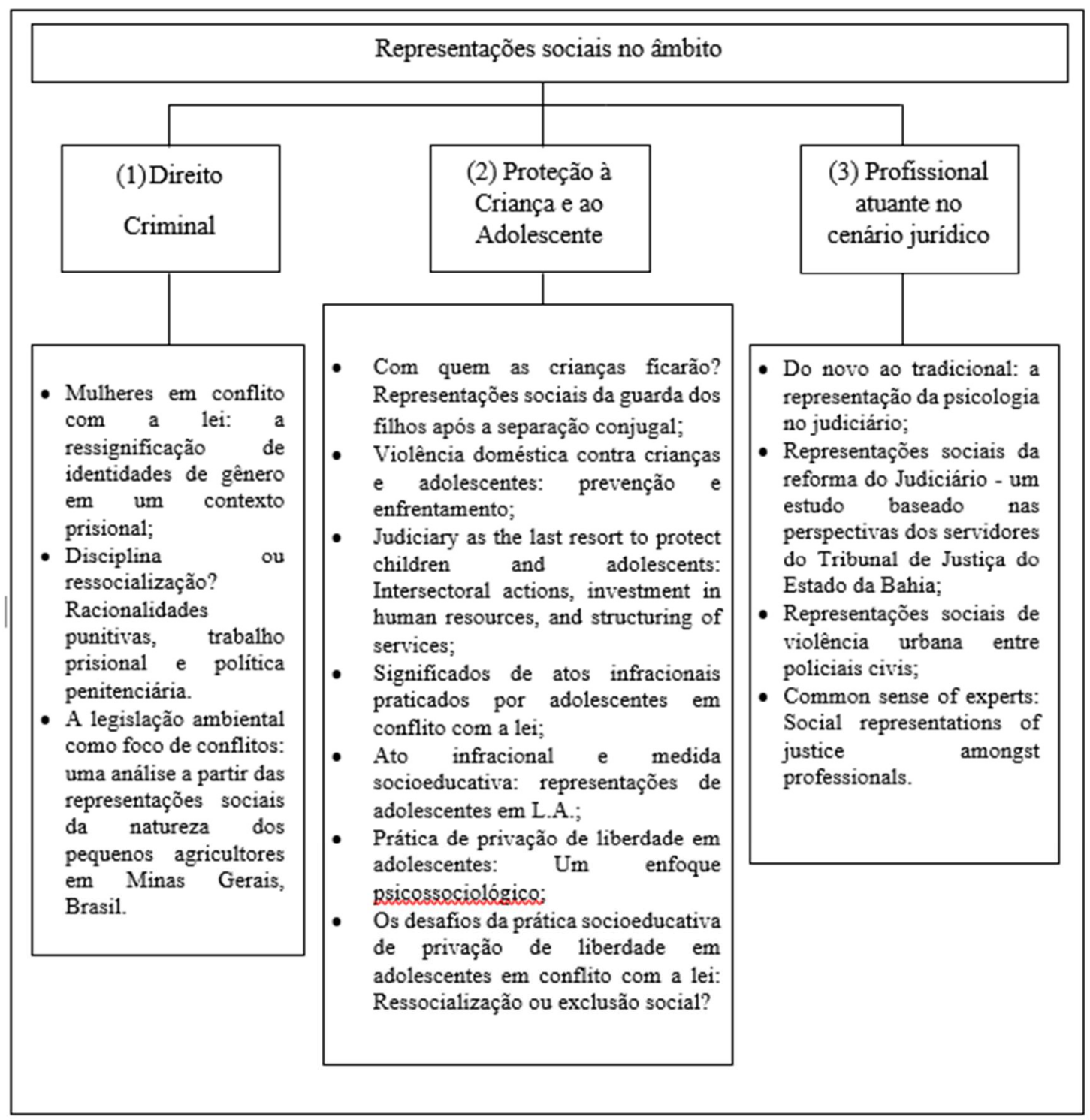

Figura 2 - Fluxo de organização da análise temática.

\section{Discussão}




\section{Direito Criminal}

A categoria 1 é compreendida por temas ligados à criminalidade, sendo dois artigos envolvendo a execução da pena e o terceiro crimes contra o meio ambiente. Oliveira (2009) trata das RS das identidades de gênero por mulheres que estão cumprindo pena em regime fechado, no qual se observou que as RS da mulher correspondem à mulher moderna, que conquista seu espaço de forma autônoma e independente, mulher guerreira, que vencem diariamente batalhas para isso. Todavia, há também a imagem da mulher submissa ao homem, vítima, rejeitada e carente da atenção masculina, observando-se, assim, identidades fragmentadas, por vezes contraditórias e desestabilizadas. Mulheres que buscam na identidade de boa mãe o reconhecimento e pertencimento social. Observou-se ainda que essas mulheres estão ressignificando algumas representações sociais, principalmente quanto à mulher presidiária na visão da sociedade e por ela excluída, gerando conflitos de identidade e via de consequência baixa autoestima, frustrações, revoltas e sentimento de exclusão, dando maior margem à reincidência e marginalização, o que reafirma o entendimento da autora Jodelet (2001) de que as representações sociais exercem influência direta das comunicações da sociedade e da mídia, criando um universo consensual.

Ainda no sistema prisional, porém sob outro ângulo, analisando as RS sobre a implantação do trabalho prisional em regime fechado no Distrito Federal, Machado e Sloniak (2015), por meio de entrevista individual qualitativa ouviram quatorze atores diretamente envolvidos na gestão, fiscalização e execução penal. Afirmam os autores que há a frustração diante da limitação da atuação e pessimismo de que nada funciona, estando a fala dos gestores movidas pela interdisciplinaridade, a dos juízes e promotores fundadas em conhecimentos dogmáticos e criminológicos e a dos executores pela prática de conviver no cotidiano com as rotinas nas prisões. Contatou-se a crença pela grande falta de prioridade e desinteresse por parte dos políticos e até mesmo falta de apoio da própria sociedade em investimentos nesse setor. Acredita-se também que um grande diferencial é a postura ativa e ousada do executor da unidade para a implantação das políticas públicas, necessitando habilidades de gestão. Outras representações estão atreladas à morosidade processual e imposição de penas de prisão por vezes desnecessárias e irrazoáveis, bem como falta de planejamento e interação entre gestores e fiscalizadores 
do sistema. Há, ainda, uma forte descrença da efetividade do trabalho prisional ante a dissonância entre o trabalho e cursos ofertados na prisão e a realidade do mercado de trabalho em liberdade, onde se valoriza o pensar e não a força braçal. Assim, observa-se uma diversidade de representações sociais, pois como indicam Morera, Padinha, Silva e Sapag (2015) as representações sociais são dinâmicas, permitindo que os pensamentos circulem e as discussões não parem, mas que ao mesmo tempo observa-se que elas culminam num senso comum de descrédito do sistema penitenciário.

No que tange ao crime ambiental, de Laschefski, Dutra e Doula (2012) investigaram as representações sociais de um grupo de 17 pequenos agricultores familiares sobre natureza. Estes agricultores veem a natureza como algo proibido, dotado de regras e regulamentos impostos pela lei e, ao mesmo tempo, também a veem como recursos naturais necessários para a subsistência familiar. Logo suas representações sociais são híbridas, entre visões modernas e tradicionais do mundo. Percebe-se que está havendo uma modificação das representações sociais da natureza, porém ainda não de forma substancial a impedir que eles violem a lei, ainda que para muitos deles essa violação ocorra por pura necessidade de subsistência material. É por meio desse campo simbólico que os agricultores interpretam a sua realidade e direcionam as suas ações entrando em choque com a legislação ambiental, pois as representações sociais determinam os comportamentos, condutas e práticas de um grupo (Morera, Padilha, Silva \& Sapag, 2015).

\section{Proteção à criança e ao adolescente}

A categoria 2 reúne sete artigos que tratam da Proteção à Criança e ao Adolescente em sentido amplo, abrangendo, por didática, inclusive questões que são discutidas judicialmente em Varas de Família, mas que têm como enfoque a criança e o adolescente. Entre os artigos que compõem essa categoria, está o estudo de Schneebeli e Menandro (2014) que realizaram pesquisa com 30 pais de filhos de até dezoito anos incompletos de idade, com o objetivo de identificar as RS da guarda de filhos no contexto atual em decorrência da edição da nova Lei de Guarda Compartilhada (Lei 11.968/08). Os autores identificaram que a guarda de filhos após a ruptura conjugal ainda é representada pelo dever de a mãe ser a guardiã, muito embora tenham demonstrado preocupação com o 
risco do distanciamento do genitor não-guardião, que apenas vê os filhos quando no momento de visitação e com a sobrecarga do guardião exclusivo. Percebe-se que essas representações sociais de que a mãe é pessoa mais bem preparada para cuidar do filho estão ancoradas no processo de integração cognitiva do objeto da guarda no pensamento social preexistente, histórico e culturalmente enraizado, pois, segundo Jodelet (2001, p.38) "a ancoragem enraíza a representação e seu objeto numa rede de significações que permite situá-los em relação aos valores sociais e dar-lhes coerência".

Branco e Tomanki, (2018) pesquisaram sobre as representações sociais de atores do Sistema de Garantia de Direito (SGD) sobre prevenção e enfrentamento da violência doméstica contra crianças e adolescentes. Para isso, os autores entrevistaram quatro conselheiros tutelares, um Promotor de Justiça e dois psicólogos, tendo observado que o enfrentamento da violência é representado pela capacidade de identificação de sinais ou indícios de situação de violência para que seja possível a realização efetiva da denúncia, bem como pela necessidade de proteção das vítimas, ancoradas na contradição de papéis da família, que se apresenta, ora como protetora, ora como violentadora, necessitando nesse caso da intervenção efetiva e certeira dos órgãos de proteção e, por fim, a responsabilização do agressor. No que tange à prevenção da violência, esta é representada pela necessidade de acompanhamento das famílias desde a maternidade, o que pode se dar por intermédio da escola e das campanhas publicitárias, ancoradas "na concepção de família enquanto organização social propícia para uma intervenção do Estado com a finalidade de coibir a violência" (Branco \& Tomanki, 2018, p. 408), principalmente as famílias em condições de risco, assim consideradas aquelas com vulnerabilidade social e, por fim, ações que visem a mitigar as consequências das violências já cometidas. Os psicólogos consideram-se responsáveis pelo enfrentamento e prevenção da violência, talvez por atuarem de forma direta nos casos, principalmente no atendimento às vítimas e à família, diferentemente dos demais interessados que consideram como responsáveis outros atores e órgãos.

Ainda no tocante à violência em face de crianças e adolescentes, no estudo de Silva, Ferriani e Silva (2012), em que foram realizadas entrevistas semiestruturadas e grupo focal com onze membros de Varas Especializadas de Crimes contra a Criança e Adolescente (VCCA), buscou-se identificar as representações sociais dos membros do 
Poder Judiciário a respeito da prevenção da violência sexual intrafamiliar contra crianças e adolescentes. O resultado apresentou duas categorias: uma delas é a representação do Judiciário como última instância, ancorada nos fatos de que, quando o Judiciário é acionado já houve a violação e busca-se apenas a responsabilização e interrupção de comportamentos violentos, ou seja, a prevenção da reincidência. A outra categoria representa o trabalho de prevenção como ações de políticas públicas realizadas de uma forma integrada por toda a sociedade, o que não ocorre principalmente diante da arbitrariedade política com que se dispõem os recursos financeiros do Estado. Em relação à estrutura e dinâmicas das Varas, estas são representadas pela morosidade decorrente da precariedade da estrutura física, necessidade de maior quantidade e qualidade de recursos humanos, principalmente especializados na área de violência contra crianças e adolescentes, em que se exige uma grande sensibilidade por parte do operador do Direito, e forma de tramitação dos processos, os quais estariam mais ligados à hierarquia (juiz) e à burocratização do Estado. Essa preocupação com a necessidade de acompanhamento da família e sensibilidade do operador do Direito demonstra a influência das representações sociais sobre as práticas dos profissionais, pois segundo Rouquete (1998) o que se faz está correlacionado com aquilo que se pensa.

Observou-se um estudo pela Teoria das Representações Sociais no campo dos adolescentes em conflito com a lei, constituído de quatro artigos, os quais possuem o mesmo objeto de estudo, entrevistas de adolescentes que cumprem medida socioeducativa de privação de liberdade. Ikuma, Kodato e Sanches (2013) investigaram por meio do método das análises das representações sociais os significados e as explicações sobre os atos infracionais praticados por adolescentes em conflito com a lei, vistos por eles próprios. Mediante a entrevista de sete adolescentes, observaram que os atos infracionais são representados como instrumentos de intimidação, poder, sobrevivência, consumo e possibilidade de inclusão social, ancorados nos preceitos ditados pelo crime organizado. Nesse mesmo sentido Coelho e Rosa (2013) analisaram as representações sociais de adolescentes sobre os atos infracionais e sobre as medidas socioeducativas a eles aplicadas, por meio de entrevista de 46 adolescentes. As representações sociais de infração foram cadeia e crime, estando também relacionadas aos tipos de infrações e às suas causas e consequências vivenciadas, ao passo que as 
representações sociais das medidas socioeducativas estavam vinculadas ao caráter educativo e à possibilidade de mudança. Percebe-se, assim, a importância da função identitária das RS explicada por Abric (1998) ao observar o controle social exercido sobre o adolescente por meio das representações sociais compartilhadas que definem a identidade do grupo, fazendo com que o adolescente se sinta incluído no grupo.

Diversamente demonstrou a pesquisa de Coutinho, Estevam, de Araújo e Araújo (2011), realizada com 50 adolescentes, sobre a prática socioeducativa de privação de liberdade, na qual se observou uma prevalência pela representação não ressocializadora da instituição, permeada de elementos de insegurança, medo e violência, numa espera institucional tensa, representada como um local de expiação e castigo, onde a imagem do profissional técnico é de amigo, ao passo que a do educador é de agressor. A autopercepção é representada por alguns de forma positiva, como tranquilo, bondoso e amigo, e por outros de forma negativa, como sem juízo, violento e inútil, ao passo que a percepção do adolescente sobre si mesmo condicionada ao olhar do outro é representada apenas por percepções negativas. As experiências de vidas evidenciam conflitos, tanto no contexto social, quanto no familiar, gerando manifestações de sentimentos de tristeza, angústia, vazio, perturbações do sono, problemas de alimentação e energia diminuída. Apesar de tudo, eles ainda possuem uma perspectiva de mudança de vida, na qual está presente o trabalho, o lazer, a paz e a liberdade. Observa-se nesse caso que as RS dos adolescentes estão relacionadas às práticas das relações que eles têm com os membros da instituição, trata-se da função justificadora das RS explicada por Abric (1998).

No estudo de Estevam, de Lima Coutinho e Araújo (2009), investigaram as representações sociais de 115 adolescentes em conflito com a lei sobre a prática socioeducativas de privação de liberdade. A pesquisa foi realizada em duas instituições diferentes, onde se pode observar diferenças nas representações sociais dos dois grupos. Em uma instituição, a medida socioeducativa de privação de liberdade é representada como um momento de reflexão sobre as perdas sofridas com o internamento e a instituição ressocializadora foi representada como uma prisão, a qual possui disciplina e bons profissionais. Para os adolescentes da outra instituição, a privação de liberdade é representada pelo sentimento de tristeza e angústia e a instituição ressocializadora como um local de desordem, malícia e superlotada. Observa-se que uma das principais 
diferenças resulta na ancoragem de elementos da atuação dos profissionais das instituições, sendo positiva a visão da instituição ressocializadora em uma unidade e negativa em outra.

Observa-se que os quatro estudos anteriores as representações sociais da internação aparecem ancoradas no sistema prisional, ou seja, enraizadas socialmente a este sistema. Restou clara também as representações sociais da ressocialização ancoradas na imagem dos profissionais da instituição. Assim, o diálogo pedagógico e o vínculo saudável dos profissionais para com os adolescentes são de suma importância em razão da fragilidade emocional destes pela perda dos vínculos afetivos decorrentes da internação, além de se encontrarem em um período de faixa etária de vulnerabilidade. Por vezes, segundo Abric (1998), as práticas das relações podem determinar as representações sociais de determinado grupo, de forma positiva ou de forma negativa.

\section{Profissional atuante no cenário jurídico}

Em campo diverso aparecem estudos a respeito do profissional atuante no cenário jurídico, inserido na terceira categoria do presente estudo. Sauerbronn e Sauerbronn, (2015) identificaram as representações sociais da reforma do Judiciário pela perspectiva de 236 servidores do Tribunal de Justiça do Estado da Bahia (TJBA). Os resultados apontaram a reforma como algo regencial, pautado na gestão de processos, de pessoas, de relações interpessoais, infraestrutura e valores organizacionais como a transparência e a ética, visando à melhoria dos trâmites processuais, tendo a celeridade processual ficado associada à gestão dos processos de trabalho com eficiência, eficácia e economicidade das atividades jurisdicionais. Mafra e Santos (2013), mediante entrevista de 53 psicólogos, identificaram que as representações sociais dos psicólogos do Poder Judiciário de Pernambuco sobre a Psicologia Jurídica tratam da convivência de interfaces, entre conhecimentos que estão em construção, tanto científico, quanto comum, onde o respeito ao compromisso ético para com a instituição e para com os sujeitos atendidos se sobressai, principalmente em razão da grande demanda de conflitos e da realização de pareceres. Também foram observadas representações da psicologia jurídica pelos termos ajuda e escuta. Constata-se nesses dois estudos as práticas sociais de compromisso para 
com o jurisdicionado, de acordo com Abric (1998) as RS têm função de guiar as práticas sociais, a espécie de estratégia cognitiva que será adotada pelo grupo.

Ao passo que Almeida e Santos (2013), objetivando compreender as representações sociais da violência urbana entre policiais civis do Recife e a relação destas com suas práticas profissionais, realizaram uma pesquisa desdobrada em duas fases, sendo a primeira com base em questionário de associação livre respondido on line por cento e oito policiais, no qual a violência urbana foi representada pela ideia de homicídio, roubo e tráfico de drogas. Referida pesquisa serviu de base ao aprofundamento do estudo na segunda fase, a qual consistiu em entrevista individual de outros 12 policiais, tendo como resultado: a necessidade de valorização e formação do policial, na mudança das práticas policiais, algumas com reflexo positivo e, outras, negativo, como a falta de liberdade de ação dos policiais; a famílias "desestruturada"; causas de consequências da violência, sendo as principais a desigualdade social e as drogas; e, por fim, os procedimentos policiais, principalmente os utilizados nas abordagens, tendo sido a violência policial ressaltada mais no sentido de ser necessária para a proteção dos próprios policiais. O autor ressalta que "ao atribuírem a causa da violência ao Estado, à pobreza, à família, os policiais afastam de si qualquer responsabilidade sobre o fenômeno, ao mesmo tempo que se colocam fora do grupo potencialmente violento" (Almeida \& Santos, 2013, p. 86).

Ainda sobre a análise da experiência diária profissional, Rochira (2014) analisou as representações sociais de justiça de dois grupos diversos de profissionais de justiça que trabalham junto aos jovens. $\mathrm{O}$ objetivo de entrevistar profissionais que trabalham no âmbito judicial era verificar como as práticas sociais influenciam nas RS de justiça. Houve diferenças de representações entre os dois grupos, para um deles há diferença entre o sistema jurídico adulto e o juvenil, sendo no adulto o termo justiça é representado pelo egoísmo, em que se utiliza da lei para atingimento do interesse próprio e do poder, considerando a justiça um produto humano, refletindo as fraquezas dos seres humanos. Para o outro sistema jurídico, o juvenil, a justiça está representada como virtuosa, atendendo as necessidades dos jovens infratores e não a simples aplicação da lei. $O$ segundo grupo de profissionais constrói uma teoria de justiça mais reificada, baseada na contraposição, onde há a justiça institucional, interna, que envolve os jovens infratores 
que estão ali recolhidos, e a justiça institucional externa, na qual está inserida a sociedade em geral. Observa-se neste caso a função identitária das RS, uma vez que as RS de justiça variam em cada grupo estudado conforme a rede específica de relações simbólicas que servem de ancoragem para os sujeitos. Segundo Abric (1998), a função identitária das RS definem a identidade e permitem a proteção da especificidade dos grupos sociais.

\section{Considerações finais}

O objetivo do presente trabalho foi analisar a utilização da Teoria das Representações Sociais no âmbito da Psicologia Forense, para compreender o quanto os pesquisadores têm investigado por meio dessa teoria o conhecimento consensual e quanto este último tem influenciado o conhecimento reificado, a tomada de decisões e, como consequência, os comportamentos das pessoas dentro do cenário jurídico. Diante dos artigos científicos encontrados e analisados pode-se observar que há diálogos estabelecidos entre a Teoria das Representações Sociais e a Psicologia Forense, com uma grande ênfase no âmbito sócioeducativo das crianças e adolescentes, seja como vítima ou autor de ato infracional. Em seguida aparece a atuação profissional no âmbito jurídico e, artigos no âmbito da execução da pena.

Este estudo certamente não abrangeu todos os artigos científicos sobre o tema, restringindo-se às bases de dados utilizadas, a utilização de termos mais abrangentes na seleção das palavras-chave e a aos critérios de seleção previamente definidos, mas traz importantes contribuições para o Direito e para a Psicologia Forense.

Ressalta-se que não foram encontrando estudos, de acordo com os critérios selecionados, sobre matéria trabalhista, previdenciária e tributária, sendo que em relação à matéria cível, apenas foram encontrados estudos ligados à área de família. Também não foram encontrados estudos sobre os magistrados. Observa-se ainda que embora o campo do Direito Criminal seja muito estudado pela Psicologia Forense, ela pouco se utiliza para isso da Teoria das Representações Sociais, estando os estudos encontrados mais restritos à execução das penas e não tanto direcionados à perspectiva dos infratores da lei, por exemplo, a fim de estudar como eles pensam e interpretam coletivamente as relações 
interpessoais, o que poderia agregar muito conhecimento aos estudos da Psicologia Forense.

Portanto, percebe-se que ainda há um campo vasto para ser explorado na Psicologia Forense pela Teoria das Representações Sociais, de forma a auxiliar cada vez mais na compreensão de como os pensamentos do senso comum são processados, organizados e compartilhados dentro da seara jurídica que é tão complexa.

Este estudo possibilitou perceber a Teoria das Representações Sociais tem sido utilizada pela Psicologia Forense, porém de forma insipiente, havendo ainda um campo vasto para ser explorado de forma a contribuir cada vez mais na compreensão de como os pensamentos do senso comum são processados, organizados e compartilhados dentro da seara jurídica que é tão complexa e dinâmica.

\section{Referências}

Abric, J.C. (1993). Central system, peripheral system: their functions and roles in the dynamics of social representations. Papers on Social Representations, 2 (2), 75-78. Recuperado de http://psr.iscte-iul.pt/index.php/PSR/article/view/126

Almeida, A. M. D. O. (2009). Abordagem societal das representações sociais. Sociedade e Estado, 24(3), 713-737. doi: 10.1590/S0102-69922009000300005.

Almeida, L. F., \& Santos, M. F. S. (2013). Representações sociais de violência urbana entre policiais civis. Psicologia: teoria e prática, 15(2), 76-91. Recuperado de http://pepsic.bvsalud.org/scielo.php?script=sci_arttext\&pid=S151636872013000200 006\&lng=pt\&tlng=pt.

Branco, M. A. O., \& Tomanik, E. A. (2012). Violência doméstica contra crianças e adolescentes: prevenção e enfrentamento. Psicologia \& Sociedade, 24(2), 402-411. doi: $10.1590 / \mathrm{S} 0102-71822012000200018$.

Brasil. CNJ. Resolução n.75. Dispõe sobre os concursos públicos para ingresso na carreira da magistratura em todos os ramos do Poder Judiciário Nacional. Recuperado de https://atos.cnj.jus.br/atos/detalhar/atos-normativos?documento $=100$. 
Bussinger, R., \& Novo, H. (2008). Trajetória de vítimas da violência: dor e solidariedade entre mães de uma associação do Espírito Santo. Revista Psicologia Política, 8(15), 107-120. Recuperado

de http://pepsic.bvsalud.org/scielo.php?script=sci_arttext\&pid=S1519549X2008000100008\&lng=pt\&tlng=pt.

Coelho, B. I. \& Rosa, E. M. (2013). Ato infracional e medida socioeducativa: representações de adolescentes em LA. Psicologia \& Sociedade, 25 (1), 163-173. doi: $10.1590 / \mathrm{S} 0102-71822013000100018$.

Coutinho, M.P. L., Estevam, I. D., Araújo, L. F. \& Araújo, L. S. (2011). Prática de privação de liberdade em adolescentes: um enfoque psicossociológico. Psicologia em Estudo, 16(1), 101-109. doi: 10.1590/S1413-73722011000100012.

Diniz, M. H. (2000). Compêndio de Introdução à Ciência do Direito. São Paulo: Saraiva.

Eloy, C. B. (2010). A representação social do abuso sexual infantil no contexto judiciário. Revista de Psicologia da UNESP, 9 (2), 66-78. Recuperado de http://seer.assis.unesp.br/index.php/psicologia/issue/view/31.

Estevam, I. D., Lima Coutinho, M. d. P., \& de Araújo, L. F. (2009). Os desafios da prática socioeducativa de privação de liberdade em adolescentes em conflito com a lei: Ressocialização ou exclusão social? PSICO, 40(2), 64-72, Recuperado de http://revistaseletronicas.pucrs.br/revistapsico/ojs/index.php/revistapsico/article/vie $\underline{\mathrm{w} / 1440 / 4143}$.

França, F. (2004). Reflexões sobre psicologia jurídica e seu panorama no Brasil. Psicologia: teoria e prática, 6(1), 73-80. Recuperado de http://pepsic.bvsalud.org/scielo.php?script=sci_arttext\&pid=S151636872004000100 $006 \& \operatorname{lng}=\mathrm{pt} \& \mathrm{t} \operatorname{lng}=\mathrm{pt}$.

Gomide, P. I. C. (2016). Áreas de Atuação da Psicologia Forense. In P. I. C. Gomide, \& S. S. Staut Junior, (Org.). Introdução à Psicologia Forense (pp.15-32). Curitiba: Juruá.

Ikuma, D. M., Kodato, S. \& Sanches, N. A. (2013). Significados de atos infracionais praticados por adolescentes em conflito com a lei. Revista de Psicologia da UNESP, 12(1), 51-63. Recuperado de 
http://pepsic.bvsalud.org/scielo.php?script=sci_arttext\&pid=S1984$\underline{90442013000100006 \& \operatorname{lng}=\text { pt\&tlng=pt. }}$

Jodelet, D. (2001). Representações sociais: um domínio em expansão. In D. Jodelet, (Org.). As Representações sociais (pp.17-44). Rio de Janeiro, RJ: Eduerj.

Kolind, T., Frank, V. A., Lindberg, O., \& Tourunen, J. (2015). Officers and drug counsellors: new occupational identities in nordic prisons. British Journal of Criminology, 55(2), 303-320. doi: 10.1093/bjc/azu088.

Lago, V. M., Amato, P., Teixeira, P. A., Rovinski, S. L. R. \& Bandeira, D. R. (2009). Um breve histórico da psicologia jurídica no Brasil e seus campos de atuação. Estudos de $\begin{array}{lll}\text { Psicologia. 26(4), } & \text { 483-491. Recuperado de }\end{array}$ http://www.scielo.br/pdf/estpsi/v26n4/09.pdf.

Lahlou, S. (2014). Difusão das Representações e Inteligência Coletiva Distribuída In A.M.O. Almeida; M.F.S. Santos, \& Z.A. Trindade (Orgs) Teoria das Representações Sociais: 50 anos (pp. 77-130). Brasilia: Technopoliytik

Laschefski, K. A., Dutra, C., \& Doula, S. M. (2012). A legislação ambiental como foco de conflitos: uma análise a partir das representações sociais da natureza dos pequenos agricultores em Minas Gerais, Brasil. Sociedade \& Natureza, 24(3), 405-417. doi: $10.1590 /$ S1982-45132012000300003.

Levine, M., W., L., Levine, D., G., D. Levine, W. (2019). Levine, and Goldfarb's Psychological Problems, Social Issues and the Law. Recuperado de https://online.vitalsource.com/\#/books/9781684675364

Lima, M. A. A., \& Mota, F. M. M. (2015). 'Crime, Castigo e Recuperação': como adolescentes são representados em uma série de reportagens de uma TV brasileira. Intercom: Revista Brasileira de Ciências da Comunicação, 38(1), 213230. doi: 10.1590/1809-58442015110.

Machado, B. A. \& Sloniak, M. A. (2015). Disciplina ou ressocialização? Racionalidades punitivas, trabalho prisional e política penitenciária. Revista Direito $G V, 11$ (1), 189222. doi:10.1590/1808-2432201509. 
Machado, B. A., \& Porto, M. S. G. (2015). Homicídio na área metropolitana de Brasília: representações sociais dos delegados de polícia, promotores de justiça e magistrados. Sociologias, 17(40), 294-325. doi: 10.1590/15174522-017004012.

Mafra, V. C. A. S., \& Santos, M. F.S. (2013). Do novo ao tradicional: a representação da psicologia no judiciário. Estudos e Pesquisas em Psicologia, 13(2), 545-562. Recuperado de http://pepsic.bvsalud.org/scielo.php?script=sci arttext\&pid=S1808$\underline{42812013000200009 \& \operatorname{lng}=p t \& t \operatorname{lng}=p t .}$

Manso, A., \& Almeida, A. (2009). Um discurso a duas vozes: potencialidades de um estudo interpretativo sobre lei e institucionalização. Psicologia: Reflexão e Crítica, 22(3), 455-465. doi: 10.1590/S0102-79722009000300017.

Marková, I. (2006). Dialogicidade e representações sociais: as dinâmicas da mente. Petrópolis: Vozes.

Moher D, Liberati A, Tetzlaff, J., Altman D. G. (2009).Preferred reporting items for systematic reviews and meta-analyses: the PRISMA statement. PLoS Med., 6(7). doi: 10.1371 /journal.pmed.1000097.

Morera, J. A. C.; Padilha, M. I.; Silva, D. G. V. \& Sapag, J. (2015). Aspectos teóricos e metodológicos das representações sociais. Texto contexto - enfermagem, 24 (4), 1157-1165. doi: 10.1590/0104-0707201500003440014.

Moscovici, S. (1982). On social representation. In: Forgas, J. P. (Ed.). Social Cognition (181-209). Londres, Inglaterra: Academic Press.

Moscovici, S. (2012). A Psicanálise, sua imagem e seu público. Petrópolis: Vozes.

Oliveira, E. P. T. (2009). Mulheres em conflito com a lei: a ressignificação de identidades de gênero em um contexto prisional. Revista Brasileira de Linguística Aplicada, 9(2), 391-414. doi: 10.1590/S1984-63982009000200003.

Oliveira, F. O. \& Werba, G. C. (2013), Psicologia social contemporânea. In Stry, M. N. (Orgs), Representações Sociais (p.104-116). Petrópolis, RJ: Vozes.

Pascal Moliner, P. \& Guimelli, C. (2015). Les représentations sociales. Grenoble: Presses Universitaires Grenoble. 
Polli, G. M., \& Camargo, B. V. (2010). A teoria das representações sociais e a abordagem estrutural. In J. Segata, N. Machado, E. C. Mandroi \& E. R. Goetz (Eds.), Psicologia: Inovações (pp. 13-41). Rio do Sul, SC: Editora Unidavi

Polli, G. M., \& Camargo, B. V. (2015). Social Representations of the Environment in Press Media. Paidéia (Ribeirão Preto), 25(61), 261-269. doi: 10.1590/198243272561201514

Polli, G. M., \& Wachelke, J. (2013). Confirmação de centralidade das representações sociais pela análise gráfica do questionário de caracterização. Temas em Psicologia, 21(1), 97-104.

Quintero, L. A. M., \& López, E. G. (2010). Psicologia Jurídica: que hacer y desarrollo. Revista Diversitas - Perspectivas em Psicologia, 6(2), 237-256. Recuperado de http://www.scielo.org.co/pdf/dpp/v6n2/v6n2a04.pdf

Ráo, V. (1999). O Direito e a Vida dos Direitos. São Paulo: Editora Revista dos Tribunais.

Rochira, A. (2014). Common sense of experts: Social representations of justice among professionals. Integr Psychol Behav Sci, 48 (3): 239-69. doi: 10.1007 / s12124-0149257-3.

Rouquette, M-L. (1998). Representações e práticas sociais: Alguns elementos teóricos. In A.S.P. Moreira \& D.C. de Oliveira (Orgs.), Estudos interdisciplinares de representação social, (pp.39-46). Goiânia: AB Editora.

Rumin, C. R., Barros, G. I. F., Cardozo, W. R., Cavalhero, R., \& Atelli, R. (2011). O sofrimento Psíquico no trabalho de vigilância em prisões. Psicologia: Ciência e Profissão, 31(1), 188-199. doi: 10.1590/S1414-98932011000100016.

\section{Sá, C. P. (2002). Núcleo Central das Representações Sociais. Petrópolis: Vozes.}

Sauerbronn, F. F., \& Sauerbronn, J. F. R. (2015). Representações sociais da reforma do Judiciário - um estudo baseado nas perspectivas dos servidores do Tribunal de Justiça do Estado da Bahia. Revista de Administração Pública, 49(3), 719-737. doi: $\underline{10.1590 / 0034-7612130108}$ 
Schneebeli, F. C. F., \& Menandro, M. C. S. (2014). Com quem as crianças ficarão?: representações sociais da guarda dos filhos após a separação conjugal. Psicologia \& Sociedade, 26(1), 175-184. doi:10.1590/S0102-71822014000100019.

Silva, L. M. P., Ferriani, M. G. C., \& Silva, M. A. L. (2012). Judiciary as the last resort to protect children and adolescents: intersectoral actions, investment in human resources, and structuring of services. Revista Latino-Americana de Enfermagem, 20(3), 444-452. doi: 10.1590/S0104-11692012000300004.

Spink., M. J. (1993) The Concepto f Social Representations insocial Psychology. Cad. Saúde Públ., 9 (3), 300-308. 